\title{
CBR Test Sonuçlarının Üç Eksenli Deney Sonuçları İle Korelasyonunun Değerlendirilmesi
}

\author{
Mehmet Orhan $^{1}$, Ali Ateş ${ }^{2}$, Semih Şenkan ${ }^{3}$ \\ 1 Gazi ÜniversitesiTeknoloji Fakültesi İnşaat Mühendisliği Bölümü-Teknikokullar Yenimahalle/ANKARA,(ORCID:000-0003-3927-0123), orhanm@gazi.edu.tr \\ 2*Bolu Abant İzzet Baysal Üniversity, Faculty Of Engineering, Department Of Civil Engineering, Bolu, Turkey, (ORCID:0000-0001-6297-8571), aliates@ibu.edu.tr \\ ${ }^{3}$ Yüksek Teknik Yapı Öğretmeni,Eskişehir, (ORCID:0000-0002-1493-2576), senkansemih@gmail.com
}

(İlk Geliş Tarihi 20 Ağustos 2021 ve Kabul Tarihi 6 Aralık 2021)

(DOI: 10.31590/ejosat.983288)

\begin{abstract}
ATIF/REFERENCE: Orhan, M., Ateş, A. ve Şenkan, S. (2021). CBR Test Sonuçlarının Üç Eksenli Deney Sonuçları İle Korelasyonunun Değerlendirilmesi. Avrupa Bilim ve Teknoloji Dergisi, (31), 61-70.

ÖZ

Bu çalışmada Ankara'nın Çukurambar semtinden alınmış yüksek plastisiteli kil ile farklı su içeriklerinde standart Proctor enerji oranında sıkıştırılarak hazırlanmış deney numunelerinin CBR değerleri ile drenajsız kayma dayanımı parametreleri arasındaki ilişki araştırılmaya çalışılmıştır. Bu nedenle yapılan standart Proctor deneyi ile zeminin optimum su içeriği ( $\mathrm{w}_{\mathrm{opt}}$ ) bulunmuştur. Kuru ve ıslak CBR deneyi şartlarının araştırıldığı çalışmada, ıslak CBR deneyi öncesi, zemin doygun hale getirilemediğinden doygunluk şartlarını temsil etmesi için optimum su içeriği, \%10 arttırılarak doygunluk yüzdesi $(\mathrm{Sr})$ yaklaşık $\% 95$ 'e, \%10 daha arttırılarak zemin doygunluk yüzdesi yaklaşık \%98 \%100 değerlerine yaklaştııılmış ve bu su içeriklerinde sıkıştırılarak şartlar sağlanmaya çalışılmıştır. Değişik su oranı içeriklerinde hazırlanmış deney gruplarından her birinden 4 adet ve toplam 12 numune üzerinde CBR deneyi yapılmıştır. Hazırlanan bu numunelerden yaklaşık 35 adet de üç eksenli basınç deney numunesi alınmış ve bu numunelere üzerinde drenajsız konsolidasyonsuz (UU) üç eksenli basınç deneyleri yapılmıştır. Deney sonunda, killi zeminlerde su içeriği, CBR ve drenajsız kayma dayanımı parametreleri arasındaki ilişsi ortaya konulmaya çalışılmıştır.
\end{abstract}

Anahtar kelimeler: CBR, UU üç eksenli test deneyi, Ankara Çukurambar killer

\section{Assessment of Correlation of CBR Test Results and Triaxial Test Results}

\begin{abstract}
Is this study the relation between the parameters undrained shear strength and CBR values of sample prepared compacting at a different energy rates and in different water content of standard Proctor and modified Proctor test on the samples obtianed from Çukurambar area in Ankara. For this reason, the optimum water content was found by the Standard and Modified Proctor test performed. In the study, in dry and wet conditions, before the wet CBR, as the test is not provied in saturated conditions, first the water content is increassed at a rate of 10 percent of water to attain the 95 percent saturation and second the water content is increased at arate of 10 percent of water to attain the 98 percent saturation conditions and then the conditions are supplied to attain compacting at these water rates. A total of 12 samples presenting the 4 samples for each kinds of soils were performed on CBR tests at diffrent energy and water content rates. Approximately a total of 35 samples obtained from these sample prepared were conducted the three axial tests on the conditions that it is undreained unconsolidated environment. In the conclusion, the relation between CBR and undrained shear strength parameters were studied to reveal boundind variation of energy rates and water content rates in clayey soils in these conditions.
\end{abstract}

Keywords: CBR, UU triaxial compression test, Ankara çukurambar

\footnotetext{
* Sorumlu yazar: aliates@ibu.edu.tr
} 


\section{Giriş}

Ülkemiz coğrafi olarak deprem tehlikesi açısından riskli bir konumdadır. Bu nedenle zeminler üzerindeki yapıları güvenli bir şekilde taşıyabilmeli ve yeterli taşıma gücüne sahip olması gerekmektedir. Şayet üzerinde yapılması planlan zeminler yeterli düzeyde taşıma gücüne sahip değilse, zeminler değișik yöntemlerle iyileştirilmelidir. İyileştirme yöntemlerininin kontrol edilmesi aşamasında CBR yöntemi, özellikle yol yapımı uygulamalarında dünyada ve ülkemizde oldukça geniş ölçek de kullanılmaktadır [1]. Bu çalışma kapsamında Ankara ili Çukurambar semtinden alınan yüksek plastisiteli killere kompaksiyon ve drenajsız konsolidasyonsuz (UU) üç eksenli basınç deneyleri uygulanmıştır [2]. Bu konuda literatürde oldukça geniş çalışmalar mevcuttur. Türedi v.d. [3] "Celikhane Cürufu Katkısının CBR Sonuçlarına Etkisini” Araştırılmışlardır. $\mathrm{Bu}$ çalışmada kullanılan curufun doğal kil zeminlere eklenmesi durumunda kil zeminlerin CBR değerlerinde artış olduğunu ortaya koymuşlardır. Vural [4] yaptığı çalışmada inşaat enkaz ve yıkıntı atıklarının CBR deneyi ile taşıma gücüne etkisini araştırmıştır. $\mathrm{Bu}$ çalışma ile inşaat atıklarının taşıma gücünü artırdığını ve tekrar kullanılabilirliğini ortaya koymuştur. Erginer v.d.[5] atık lastik tozu ile CBR değerlerini araştırmışlardır. Yaptıkları çalışma ile CBR deneyleri sonucunda, lastik katkının \%20 oranlarına kadar zemine ilave edilmesiyle CBR değerini arttığını ortaya koymuşlardır. Kök v.d. [6] "Çimento Stabilizasyonun Zeminlerin Esnek Üstyapı Maliyetine Etkisi" adlı çalışmasında çimento oranındaki artışın yumuşak zeminlerin hem taşıma gücünü hem de CBR değerini artırdığını belirtmiştir. Yaşar [7] uçucu kül katkısının killerin geoteknik özelliklerine etkisi ile ilgili çalışmasında uçucu külün zemin geoteknik özelliklerinin gelişmesinde ve CBR değerlerinde artışın olduğunu yaptı̆̆ tezinde belirtmiştir. Geçkil [8] karbon katkısı ile yaptı̆̆ zemin iyileştirme çalışmasında, karbon katkısının CBR değerinde artış meydana getirdiğini kaydetmiştir.

Burada kullanılan killi zeminlerin doygun şartlara yaklaştıç̧a CBR değerlerindeki değişimleri ve bu değişimlerden zemin kayma dayanım parametrelerinin nasıl etkilendiğini görmek amacı ile zeminler, optimum su içeriğginde ve optimum su içeriğinin üzerindeki su içeriklerinde doygunluk yüzdeleri $\% 98$ ile $\% 100$ arasındaki değerlere getirilerek standart Proctor enerji oranında sıkıștırılmıștır [9]. Hazırlanan 12 adet numuneye CBR ve bu numunelerden alınan yaklaşık 35 örnek üzerinde üç eksenli basınç deneyleri yapılmış, bu iki deneyin sonuçları arasında korelasyon kurulmaya çalışılmıştır. Bulunan sonuçlar daha önce yapılmış benzer deney sonuçları ile karşılaştırılmıştır.

\section{Materyal ve Metot}

\subsection{Materyal}

\subsubsection{Inceleme AlanınınTtanıtılmast}

$\mathrm{Bu}$ çalışmada Ankara ili Çukurambar bölgesinden alınan yüksek plastisiteli kil numuneleri kullanılmıştır. Numunenin alındığı yerin yer bulduru haritası Șekil 1'de verilmiștir. Ankara kilinde en çok görülen kil mineralleri, simektit, illit, klorit ve kaolinit olup azda olsa diğer kil mineralleride görülmektedir. Ankara kili montmorillonitde içermesinden dolayı şişme potansiyeli yüksek bir kildir $[10,11]$.

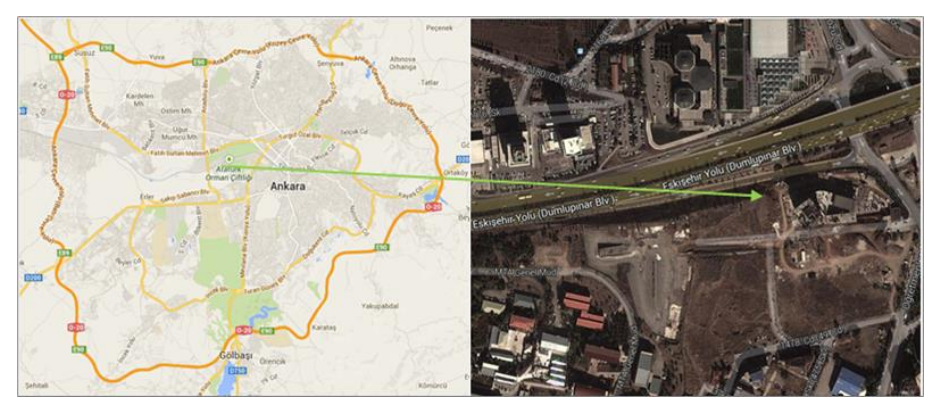

Şekil 1. Numunenin alındlğg yerin yer bulduru haritası

Zemin sınıflaması olarak genelde yüksek plastisiteli $(\mathrm{CH})$, inorganik kil $(\mathrm{OH})$ ve yüksek plastisiteli $(\mathrm{MH})$ grubundadır. Ayrica normal aktif killer grubuna girmekte, indeks ve sinıflama değerleri alüvyal kile oranla daha yüksektir. Dane dağılımları ise değişik kil minerallerinden oluştuğu için heterojen görünümdedir. Ankara kilinde yer yer kaliş katmanları ve kalker konkresyonları da görülmektedir [12,13]. Ankara ilinin genel jeololi haritası Şekil 2'de verilmiştir.

Laboratuvara getirilen örselenmiş zemin numunesine Atterberg limit deneyleri, özgül ağırlık deneyi, elek analizi ve hidrometre deneyi yapılmıştır. Zemin numunesinin optimum su içeriğini ve maksimum kuru birim hacim ağırlığını bulmak için ASTM D 698 [14]'e göre Proctor deneyi yapılmıștır. Deneyler yapılırken oluşabilecek hataları minimum düzeye indirmek ve zemine uygulanacak darbeleri homojen bir şekilde yaymak için otomatik kompaksiyon aleti tercih edilmiştir. Hazırlanan numunelere CBR deneyi yapılmıștır. Zeminin kayma gerilmesi dayanım parametrelerini ölçmek için CBR deneyi yapılan numunelerden hidrolik numune alıcı ile numuneler alınmış, bu numuneler üzerinde ASTM D 2850 [15]'e uygun olarak (UU) üç eksenli basınç deneyi yapılmıştır [16]. 


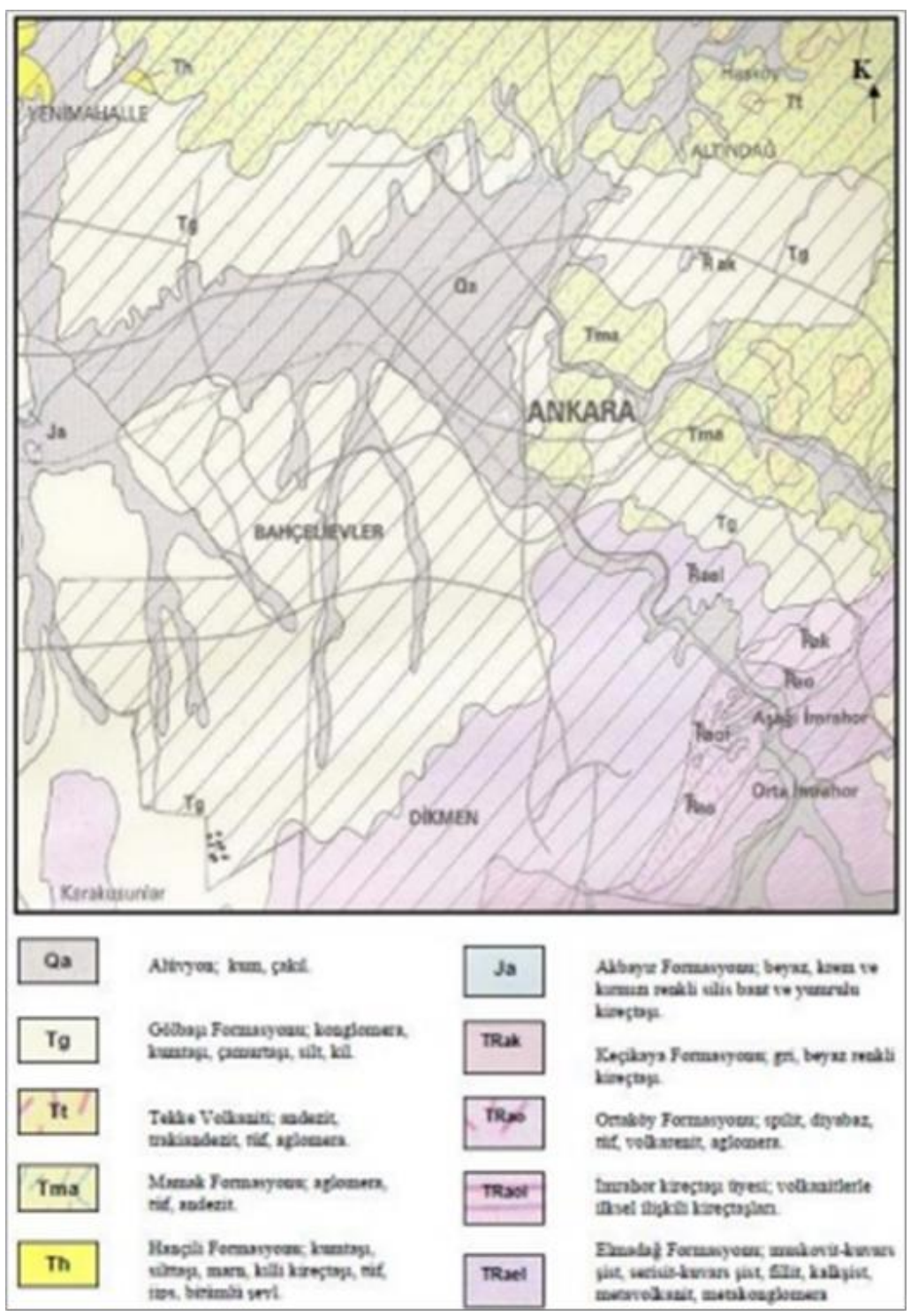

Şekil 2. Ankara ili ve çevresi 1:100 000 ölçekli genel jeoloji haritası [13]

\subsection{Metot}

$\mathrm{Bu}$ çalışmada, kuru ve sslak CBR deneyi ile elde edilen sonuçlarla Üç eksenli basınç deneyi sonuçlarının arasındaki ilişkilerin ortaya konulması planlanmıştır. Bu kapsamda CBR numunelerinin bir kısmı sslak CBR olarak planlanmış fakat, 7 gün suda bekletilen numuneler suya doygun hale gelmediği için islak CBR deneyi yerine, zeminin su içeriğinin optimum seviyesinin üzerine çıkartılarak doygun şartlara getirilmeye çalışılmış ve zeminin doygunluk derecesindeki artışların CBR ve üç eksenli basınç deney değerlerine etkisi gözlenmeye çalışılmıştır. Bu sebeple numuneler optimum su içeriğinin yanı sıra, ayrıca yaklaşık \%10 ila \%20 seviyesinin üzerinde su içeriği değerlerinde sıkıştırılmıştır. Araştırmada kullanılacak killerin, indeks ve tanımlama deneyleri bilinen metotlarla yapılmıştır. Bunlar için, araziden getirilen zemin numuneleri öncelikle Atterberg kıvam limitleri, tane dağılım analizi ve özgül ağırlık deneyi için ayrılarak etüvde $110 \mathrm{C}^{0}$ de 16 saat kurutulmuştur. Kuruyan numuneden 40 numaralı elekten elenmiş 200 gr kadar malzeme likit limit ve plastik limit sınırlarını belirlemek için, No.200 (0,075 mm) elekten geçen yaklaşı 40 gr malzeme hidrometre deneyi için ve 2,00 mm den elenmiş 100 gr kadar malzemede özgül ağırlık deneyi için ayrılmıştır.
Deneylerde kullanılacak numunenin optimum su içeriği ve doygunluk yüzdelerini bulmak için yapılan standart Proctor deneyi için $7 \mathrm{~kg}$ etüvde kurutulmuş zemin numunesi, tanelerinin zarar görmemesi için lastik tokmak ile $4,75 \mathrm{~mm}$ göz açıklığına sahip elekten geçebilecek hale gelene kadar ufaltılmıştır. Deneye belli bir su içeriği ile başlanmış ve su içeriği arttırılarak devam edilmiştir. Her bir deney setinden su içeriği için numune alınmış, deney sonunda yapılan hesaplarla optimum su içeriğine karşılık gelen kuru birim hacim ağırlık grafiği çizilmiş ve doygunluk yüzdeleri $(\mathrm{Sr} \%)$ hesaplanmıştır.

CBR deneyleri standart Proctor sıkılığında 3 farklı su içeriğinde, her bir su içeriğinde 4 adet olmak üzere toplam 12 numune üzerinde yapılmıştır. Deney sonuçları verilirken numunelerin karıştırılmaması için optimum su içeriğinde Proctor sıkılığındaki numunelere SP1 numaralı numune, optimum su içeriğinin \% 10 arttırılması ile doygunluk yüzdelerinin $\mathrm{Sr} \% 94$ civarına yaklaştırılan standart Proctor sıkılığındaki numunelere SP2, optimum su içeriğinin \% 20 arttırılması ile doygunluk yüzdelerinin $\mathrm{Sr} \% 97$ civarına yaklaştırılan standart Proctor sıkılığındaki numuneler SP3, numaralı numune olarak adlandırılmıştır. Ayrıca her bir numune kendi grubunun alt numarası ile adlandırılmıştır. Örneğin standart Proctor 
sıkılığındaki \%97 doygunluğa sahip numune SP3, aynı doygunluk $\%$ 'sinde deney yapılan 4 numuneden birinci numune için ise SP31 kısaltması kullanılacaktır. Deneylerde kullanılan kısaltmalar ve su içeriği-doygunluk yüzdesi değerleri Çizelge 1'de gösterilmiştir.

Çizelge 1. Deneylerde kullanılan kısaltmalar ve su içeriği-doygunluk değerleri

\begin{tabular}{|c|c|c|c|c|}
\hline Enerji Oranı & $\begin{array}{l}\text { Su İçeriği } \\
\text { (w) }\end{array}$ & $\begin{array}{c}\text { Doygunluk } \\
\text { (\%) } \\
\text { (ort) }\end{array}$ & $\begin{array}{c}\text { Hazırlanan } \\
\text { Numune } \\
\text { Adedi }\end{array}$ & $\begin{array}{l}\text { Numuneye } \\
\text { verilecek Ad }\end{array}$ \\
\hline \multirow{9}{*}{ 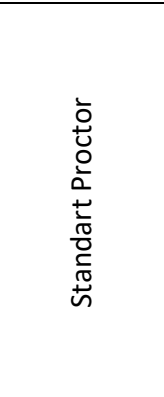 } & \multirow{4}{*}{$\begin{array}{c}\% 32 \\
\left(W_{\text {opt }}\right)\end{array}$} & \multirow{4}{*}{$\% 90$} & \multirow{4}{*}{4} & SP1-1 \\
\hline & & & & SP1-2 \\
\hline & & & & SP1-3 \\
\hline & & & & SP1-4 \\
\hline & \multirow{4}{*}{$\% 34$} & \multirow{4}{*}{$\% 94$} & \multirow{4}{*}{4} & SP2-1 \\
\hline & & & & SP2-2 \\
\hline & & & & SP2-3 \\
\hline & & & & SP2-4 \\
\hline & $\% 36$ & $\% 97$ & 4 & SP3-1 \\
\hline
\end{tabular}

Hazırlanan her bir CBR numunesinden deney sonunda 3 adet üç eksenli basınç deneyi numunesi alınmış, yaklaşık 36 numune üzerinde üç eksenli basınç deneyi yapılmıştır. Standart Proctor sıkılığında optimum su içeriğinde $(\mathrm{w}=\% 30,5), \mathrm{Sr} \% 90$ civarında, su içeriği yaklaşık \%10 arttırıldığında $(\mathrm{w}=\% 34)$, Sr ortalama \%94 civarında, ve su içeriği yaklaşık \%20 arttırıldığında ( $\mathrm{w}=\% 36), \mathrm{Sr}$ ortalama $\% 97$ civarında olmaktadır.

\section{Deneysel Bulgular}

\section{1. İndeks ve Tanımlama Deneyleri}

Numuneler üzerinde yapılan indeks ve tanımlama deneylerine göre likit limit \%80, plastik limit \%36, plastisite indisi 44 bulunmuştur. Özgül ağırlık deney sonucu Gs:= 2,65 dir.

Yapılan elek analizi ve hidrometre deney sonuçlarına göre zemin cinsi CH (USCS'ye göre) bulunmuştur. Elek analizi ve hidrometre deney sonuçları Şekil 3'de, Atterberg limitleri ve özgül ağırlık deney sonuçları ise Çizelge 2'de verilmiştir.

Çizelge 2 Atterberg limitleri, özgül ă̆ırlık deney sonuçları ve zemin sınıflandırması

\begin{tabular}{|c|c|c|c|c|c|c|}
\hline Zemin Türü & Likit Limit (\%) & Plastik Limit & Plastisite İndisi & Gs & USCS & AASHTO \\
\hline Kil & 80 & 36 & 44 & 2,65 & CH & A-7-6 \\
\hline
\end{tabular}

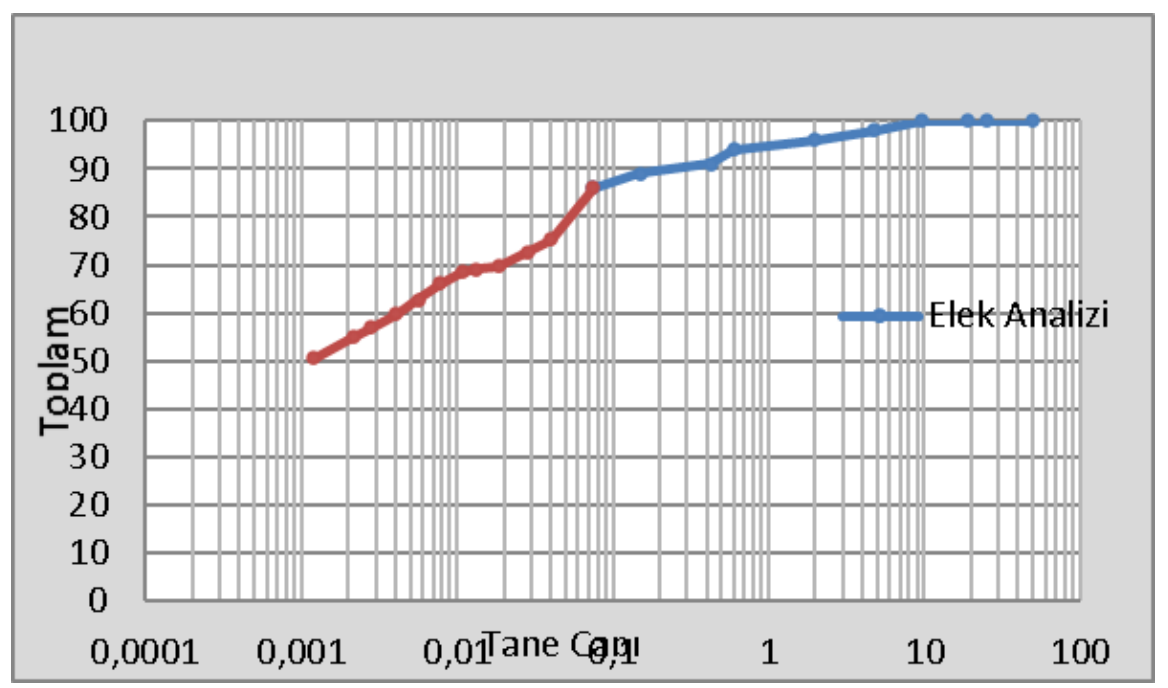

Şekil 3. Elek analizi ve hidrometre deney grafiği 


\subsection{Standart Proctor Deney Bulguları}

Çukurambar semtinden alınan ve indeks deneyleri ile türünün $\mathrm{CH}$ olduğu belirlenen kil numunesine iki kez yapılan standart Proctor deneyi ile zeminin optimum su içeriğinin ( $w_{\text {opt }}$ ) yaklaşık \%30,5 civarlarında olduğu ve bu su içeriğine karşılık gelen maksimum kuru birim hacim ağırlığın ise $1,45 \mathrm{t} / \mathrm{m}^{3}$ ve zeminin kuru birim hacim ağırlığının maksimum olduğu noktada doygunluk yüzdesinin ( $\mathrm{Sr}$ ) \%91 civarında olduğu belirlenmiştir. Standart Proctor deneyine ait $\gamma_{\mathrm{k}}-\mathrm{w}$ grafiği Şekil 4'de verilmiştir. Standart ve modifiye Proctor deney sonuçlarının sayısal verileri Çizelge 3'de verilmiştir.

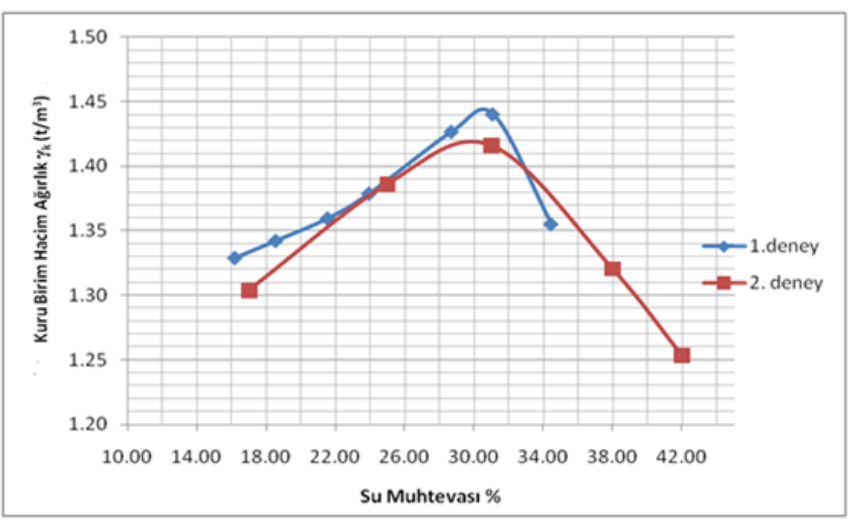

Şekil 4. Standart Proctor deney sonuçları

Çizelge 3. Standart Proctor deney sonuçları

\begin{tabular}{|c|c|c|c|c|}
\hline Deney & $\begin{array}{c}\text { Örselenmiş Numune }(\gamma) \\
\left(\mathrm{t} / \mathrm{m}^{3}\right)\end{array}$ & $\begin{array}{c}\gamma_{\mathrm{kmax}} \\
\left(\mathrm{t} / \mathrm{m}^{3}\right)\end{array}$ & $\begin{array}{c}\text { Optimum Su İçeriği } \\
\left(\mathrm{W}_{\text {opt }} \%\right)\end{array}$ & $\begin{array}{c}\text { Doygunluk Oran1 } \\
\mathrm{Sr} \\
(\%)\end{array}$ \\
\hline Standart Proctor & 1,89 & 1,45 & 30,5 & $\% 93$ \\
\hline
\end{tabular}

\subsection{CBR Deneyinden Elde Edilen Bulgular}

Proctor deneyleri ile belirlenmiş ve 6'lik kalıplarda sıkıştırılmış 12 adet zemin numunesine, standart Proctor sıkılığında, farklı su içeriği ve doygunluk yüzdelerinde CBR deneyleri yapılmıştır. Yapılan deneyler optimum su içeriği civarında standart Proctor sıkılığında sıkıştırılmış zeminlerde yapılan CBR değerlerinin ortalama $\% 12$, olduğunu bu su içeriklerinin üzerine çıkıldıkça CBR değerinin standart Proctor sıkılığı için \%6' ya kadar düştüğünü göstermiştir. Yapılan deneyler ve elde edilen veriler standart Proctor için Çizelge 4'de verilmiştir.

Çizelge 4. Standart Proctor sıkılı̆̆ındaki numunelerin su içeriği ve CBR değerleri

\begin{tabular}{|c|c|c|c|c|}
\hline Deney & $\begin{array}{c}\text { İstenen Su İçeriği } \\
(\%)\end{array}$ & $\begin{array}{l}\text { Elde EdilenSu İçeriği } \\
(\%)\end{array}$ & $\begin{array}{c}\mathrm{CBR} \\
(\%)\end{array}$ & $\begin{array}{c}\text { CBR } \\
\text { (Ort.) } \\
(\%)\end{array}$ \\
\hline SP1-1 & \multirow{4}{*}{$\begin{array}{l}\mathrm{W}_{\mathrm{opt}} \\
\% 30,5\end{array}$} & 31 & 12,17 & \multirow{4}{*}{$\% 12$} \\
\hline SP1-2 & & 31,5 & 11,5 & \\
\hline SP1-3 & & 31,3 & 11,9 & \\
\hline SP1-4 & & 30,8 & 12,45 & \\
\hline SP2-1 & \multirow{4}{*}{$\begin{array}{c}\mathrm{W}_{\mathrm{opt}}+\% 10 \\
\% 34\end{array}$} & 33 & 8,79 & \multirow{4}{*}{$\% 9$} \\
\hline SP2-2 & & 33,2 & 8,66 & \\
\hline SP2-3 & & 33 & 9,06 & \\
\hline SP2-4 & & 32,8 & 8,59 & \\
\hline SP3-1 & \multirow{4}{*}{$\begin{array}{l}\mathrm{W}_{\mathrm{opt}}+\% 20 \\
\% 36\end{array}$} & 35,8 & 6,83 & \multirow{4}{*}{$\% 6$} \\
\hline SP3-2 & & 35,8 & 6,76 & \\
\hline SP3-3 & & 35,4 & 5,55 & \\
\hline SP3-4 & & 35,4 & 5,88 & \\
\hline
\end{tabular}


Standart Proctor sıkılığındaki numunelerin su içeriğine bağlı olarak CBR değerlerinin değişiminin dağılımı Şekil 5'de gösterilmiştir. Dağılımda optimum su içeriğindeki numunelerin (SP1) CBR değerlerinin \%13-\%11, doygunluk yüzdesinin (Sr) \%95 civarındaki numunelerin (SP2) CBR değerleri \%9-\%8 ve doygunluk yüzdesinin ( $\mathrm{Sr}$ ) \%98 civarında olan numunelerin (SP3) CBR değerlerinin \%7-\%5 arasında değiştiği görülmektedir. Şekil 6'da standart Proctor sıkılığında sıkıştırılmış zeminlerin CBR ve doygunluk yüzdesi (Sr) değişim grafiği görülmektedir.

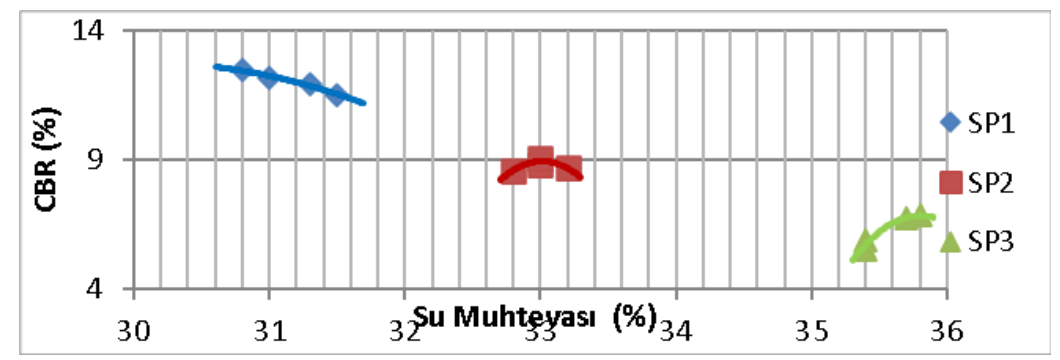

Şekil 5. Standart Proctor sıkılı̆̆ında sıkıştırılmış zeminlerin CBR ve su içeriği değişiminin grafiksel dă̆ılımı

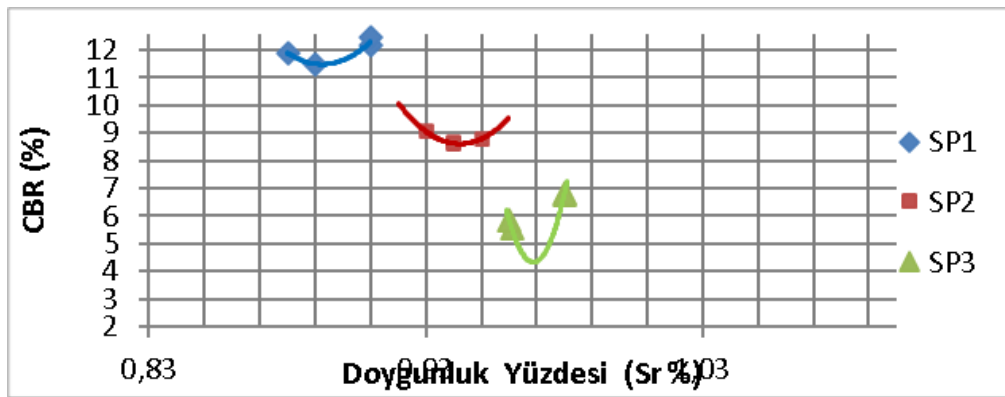

Şekil 6. Standart Proctor sıkılı̆̆ında sıkıştırılmış zeminlerin CBR ve doygunluk yüzdesi (Sr) değişiminin grafiksel dă̆ılımı

\section{4. Üç Eksenli (UU) Basınç Deneyi ve Elde Edilen Bulgular}

CBR deneyi yapılan numunelerden alınan üç eksenli basınç deneyi numuneleri ile farklı su içeriklerine ve CBR değerlerine sahip zeminlerin kayma dayanımı parametreleri arasında ilişki kurulmaya çalışılmıştır. Alınan deney numuneleri üç eksenli basınç deneyi cihazında konsolidasyonsuz drenajsız (UU) deneyine tabi tutulmuştur. Sonuçlar Çizelge 5 'de verilmiştir.
Standart Proctor sıkılığındaki zemin numunelerinin CBR değeri ve Drenajsız kayma dayanımını gösteren korelasyon grafiği Şekil 7'de verilmiştir. Standart Proctor sıkılığında ve özellikle yüksek su içeriklerindeki zeminlerde kayma düzlemi açık şekilde görülmemekte, buna karşın daha çok varilleşme görülmektedir (Şekil 8).

Çizelge 5. Standart Proctor numunelerine ait CBR ve üç eksenli basınç deney sonuçlart

\begin{tabular}{|c|c|c|c|c|c|c|c|c|}
\hline Deney & $\begin{array}{l}\text { İstenen Su } \\
\text { İçeriği } \\
(\%)\end{array}$ & $\begin{array}{l}\text { Elde Edilen } \\
\text { Su İçeriği } \\
(\%)\end{array}$ & $\begin{array}{c}\text { CBR } \\
(\%)\end{array}$ & $\begin{array}{c}\text { CBR } \\
\text { (Ort.) } \\
(\%)\end{array}$ & $\begin{array}{c}\text { Drenajsız } \\
\text { Kayma } \\
\text { Dayanımı } \\
\mathrm{Cu}(\mathrm{kPa})\end{array}$ & $\begin{array}{c}\text { Drenajsız } \\
\text { Kayma } \\
\text { Dayanımı } \\
\mathrm{Cu}(\mathrm{kPa}) \\
\text { (Ortalama) }\end{array}$ & $\begin{array}{c}\text { İçsel } \\
\text { Sürtünme } \\
\text { Açıs1 } \\
\phi\end{array}$ & $\begin{array}{c}\text { İçsel } \\
\text { Sürtünme } \\
\text { Açısı } \\
\phi \\
\text { (Ortalama) }\end{array}$ \\
\hline $\begin{array}{l}\text { SP1-1 } \\
\end{array}$ & \multirow{4}{*}{$\begin{array}{c}\mathrm{W}_{\mathrm{opt}} \\
\% 30,5\end{array}$} & 31 & 12,17 & \multirow{4}{*}{$\% 12$} & 76,73 & \multirow{4}{*}{72,86} & 25,80 & \multirow{4}{*}{26,86} \\
\hline SP1-2 & & 31,5 & 11,5 & & 72,25 & & 28,00 & \\
\hline SP1-3 & & 31,3 & 11,9 & & 68 & & 24,33 & \\
\hline SP1-4 & & 30,8 & 12,45 & & 74 & & 29,30 & \\
\hline SP2-1 & \multirow{4}{*}{$\begin{array}{c}\mathrm{W}_{\mathrm{opt}}+\% 10 \\
\% 34\end{array}$} & 33 & 8,79 & \multirow{4}{*}{$\% 9$} & 59,36 & \multirow{4}{*}{59,68} & 19,95 & \multirow{4}{*}{17,31} \\
\hline SP2-2 & & 33,2 & 8,66 & & 56,04 & & 16,02 & \\
\hline SP2-3 & & 33 & 9,06 & & 63,43 & & 15,87 & \\
\hline SP2-4 & & 32,8 & 8,59 & & 60,92 & & 17,38 & \\
\hline SP3-1 & \multirow{4}{*}{$\begin{array}{c}\mathrm{W}_{\mathrm{opt}}+\% 20 \\
\% 36\end{array}$} & 35,8 & 6,83 & \multirow{4}{*}{$\% 6$} & 58,62 & \multirow{4}{*}{56,08} & 12,09 & \multirow{4}{*}{11,95} \\
\hline SP3-2 & & 35,8 & 6,76 & & 52,39 & & 12,82 & \\
\hline SP3-3 & & 35,4 & 5,55 & & 56,51 & & 11,23 & \\
\hline SP3-4 & & 35,4 & 5,88 & & 56,8 & & 11,65 & \\
\hline
\end{tabular}




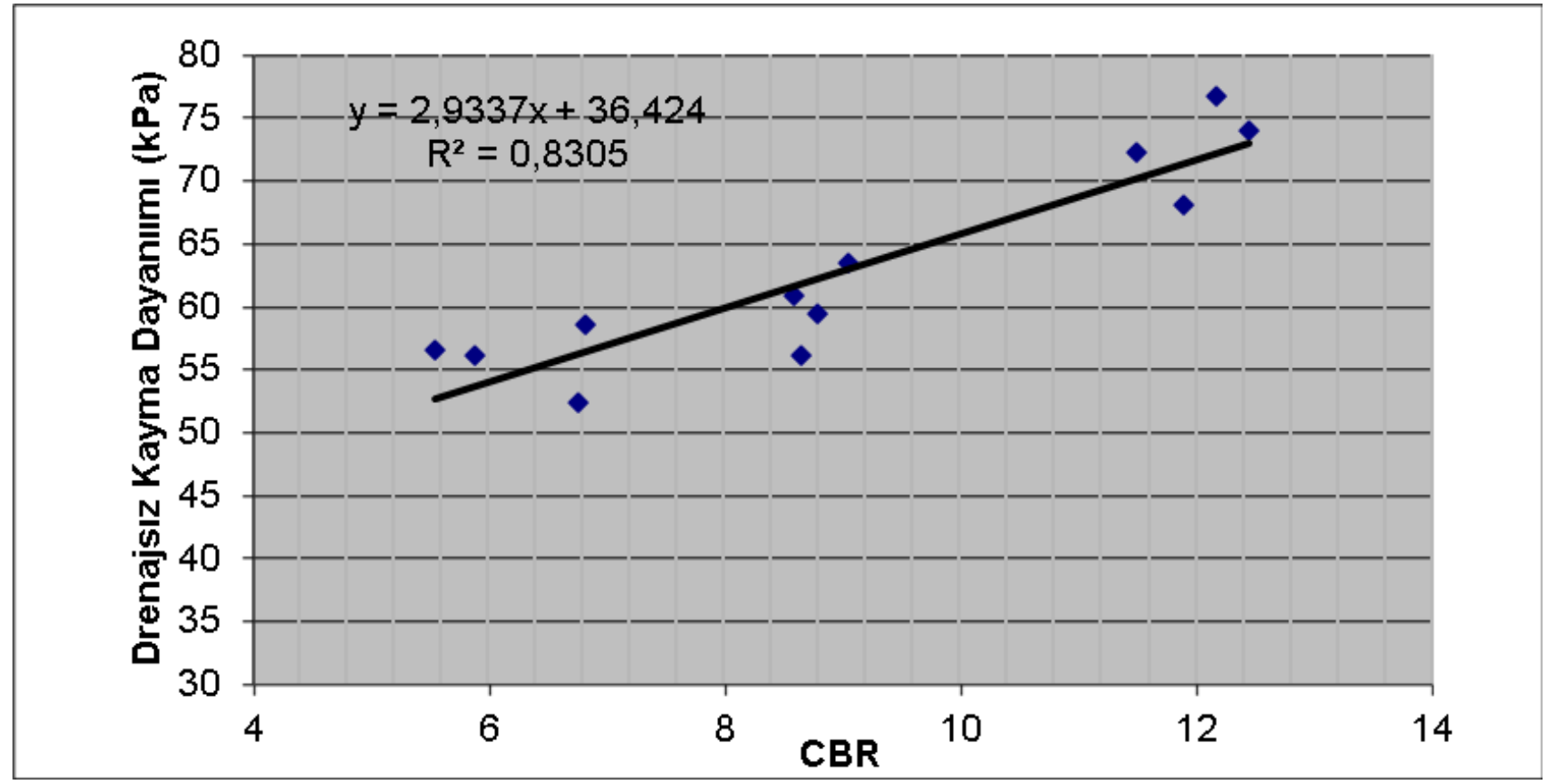

Şekil 7. Kohezyon değeri ile standart Proctor sıkllı̆̆ındaki numunelerin CBR değerlerinin korelasyon grafiği

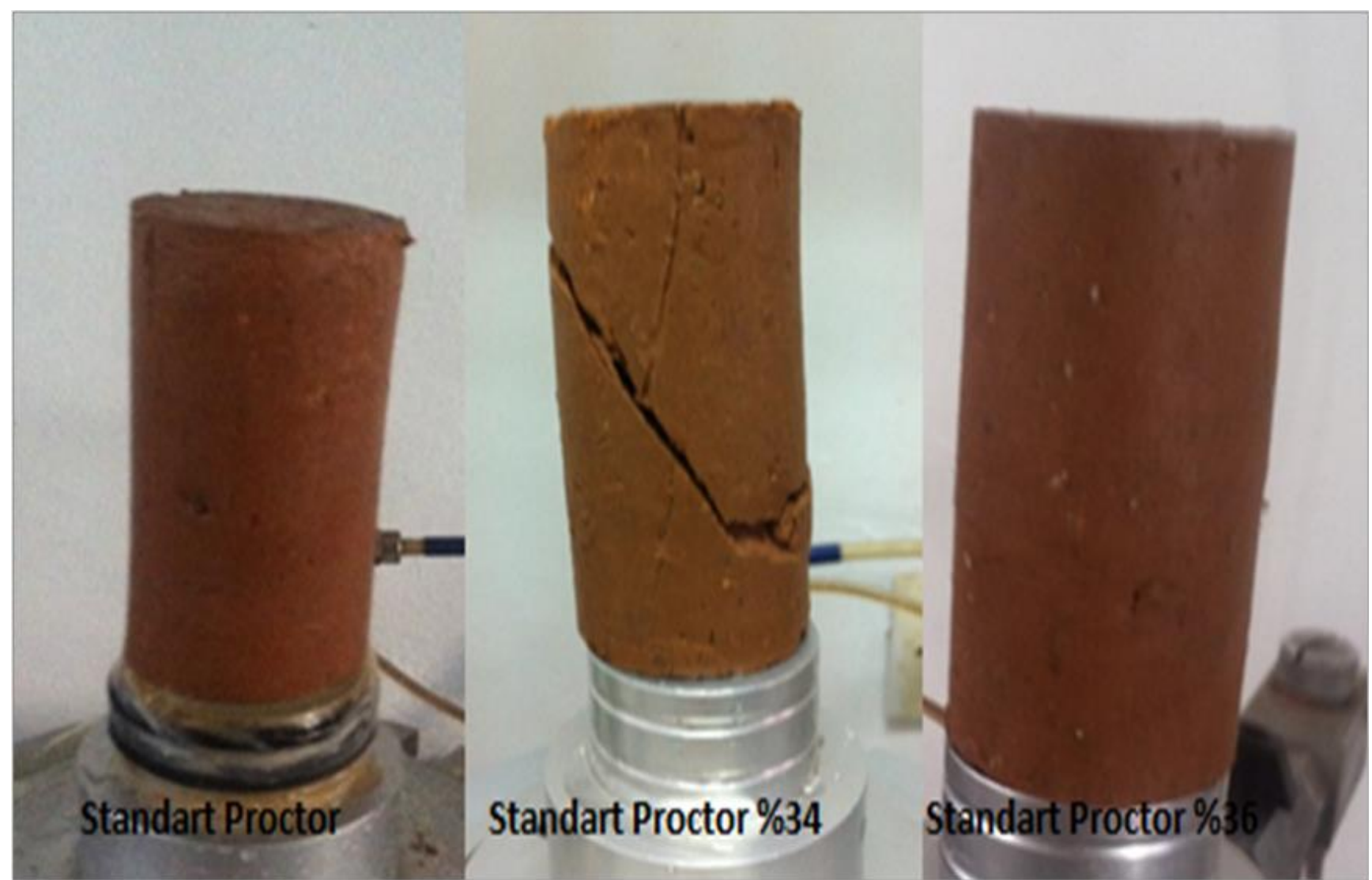

Şekil 8. Standart Proctor slkıliğındaki üç eksenli deney numuneleri

Üç eksenli basınç deneyi yapılan numunelerin her birinin gerilme deformasyon grafiği makale içerisinde verilmemiştir. Örnek olması açısından SP1-3 numaralı numunenin gerilme- deformasyon grafiği Şekil 9'da verilmiştir. Yapılan deneylerde numunelerin CBR değerlerindeki artış ile, kohezyonlarında ve içsel sürtünme açılarında (ø) anlamlı artışlar meydana gelmiştir. 


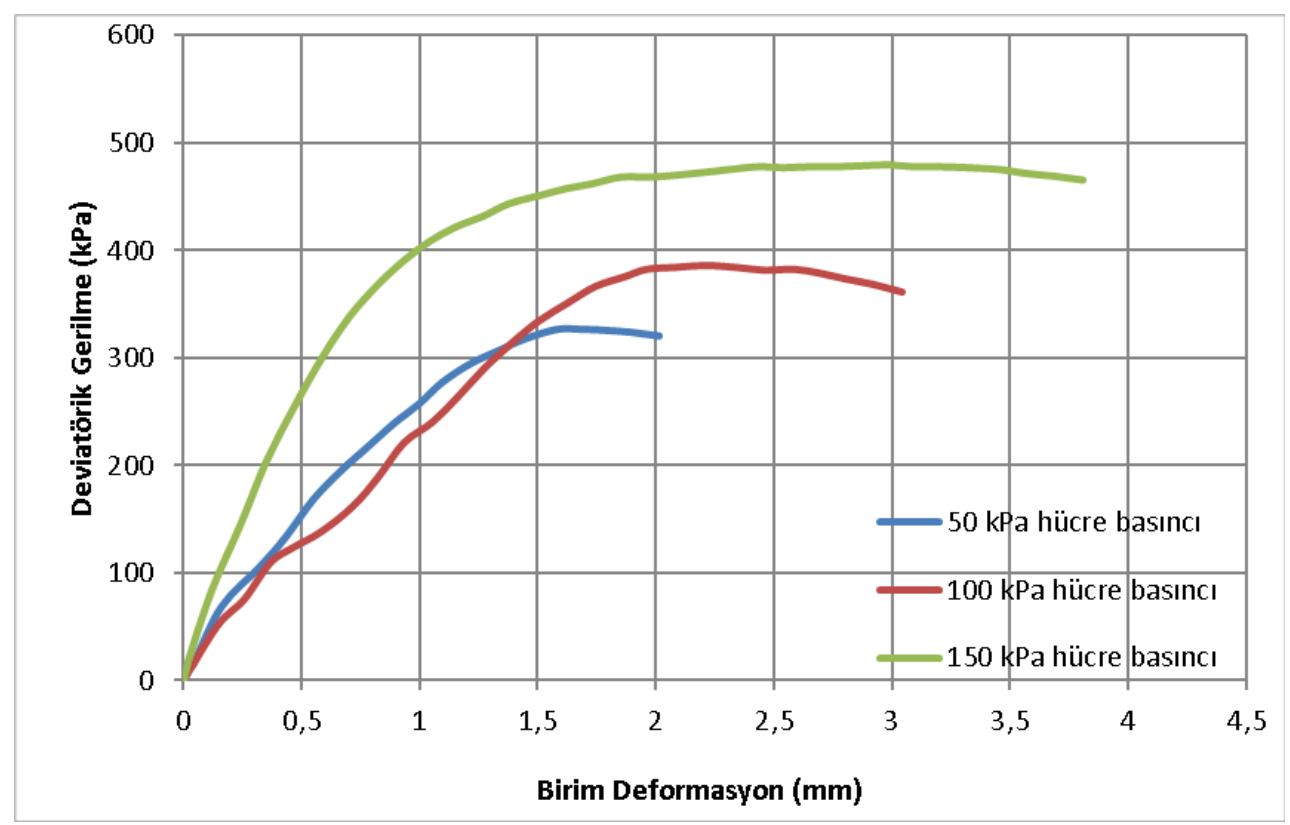

Şekil 9. SP1-3 numaralı numunenin gerilme-deformasyon grafiği

\section{Tartışma}

Bu çalışmada, yüksek plastisiteli zemin numunesinin, CBR değerleri ile sözü edilen zemininin kayma dayanımı parametreleri arasında ilişki kurulmaya çalışılmıştır. Ankara ili Çukurambar Semtinde yapılmakta olan bir inşaat kazısında alınan zemin numunesi üzerinde öncelikle tanımlama deneyleri yapılmış (elek analizi, hidrometre ve Atterberg limitleri) ve zeminin (USCS)'ye göre $\mathrm{CH}$ olarak sinıflandırılabileceği likit limitinin $\mathrm{LL}=\% 80$, $\mathrm{PL}=\% 36$, özgül ağırlığının ise 2,65 olduğu bulunmuştur. Ankara kenti toprak zeminlerinde Kasapoğlunun yaptığ $\breve{1}$ deneylerde zeminlerin özgül ağırlığının akarsu ve göl çökelleri için 2,47-2,76 arasında, alüvyonların 2,50-2,76 arasında, likit limit değerlerinin 20,50-97,50 arasında, plastik limit değerlerinin ise 5,00-58,00 arasında değiștiğini saptamıștır. Bu sonuçlarla elde edilen veriler karşılaştırıldığında sonuçların anlamlı olduğu görülmektedir. Numunelerin optimum su içeriklerini ve bu içeriklere karşılık gelen doygunluk yüzdelerini bulmak için zemin numunelerine standart Proctor deneyi yapılmış, farklı enerji oranlarına karşılık gelen optimum su içerikleri ve bu içeriklere karşılık gelen kuru birim hacim ağırlıklar bulunmuştur. Zeminin standart Proctor sıkılığında optimum su içeriğinin \%30,5 civarlarında olduğu tespit edilmiştir.

CBR deneyleri öncelikle 1slak ve kuru CBR olmak üzere iki aşamada yapılması planlanmış fakat daha sonra zeminin standartlarda belirtildiği sürede suya doygun hale gelmediği görülmüștür. Bu yüzden numuneleri doygun hale getirmek için optimum su içeriklerinin üzerindeki su içeriklerine çıkartılarak sıkıştırma deneyleri yapılmış ve doygunluk sınırına yakın değerlere göre deneyler yapılmıştır.

CBR deneyleri standart Proctor sıkılığında yaklaşık \%30,5, $\% 34, \% 36$ su içeriğinde, ve her biri 4 set olmak şartı ile toplam 12 numune üzerinde yapılmıştır. Standart Proctor sıkılığında, $\% 30,5$ su içeriğinde (CBR \% 12,2-11,5-12-12,4) ortalama \%12, $\% 34$ su içeriğinde (CBR \% 8,8-8,7-9,1-8,6) ortalama \%8,8 ve \%36 su içeriğinde ise (CBR \% 6,8-6,8-5,6-5,9)ortalama \%6 CBR değeri elde edilmiştir.

Üç eksenli basınç deneyi için CBR kalıplarında deneye tabi tutulan zemin numunelerinden her biri en az 3 tane olmak üzere hidrolik numune alıcı ile deney numuneleri alınmış ve 36 numune üzerinde deneyler yapılmıştır. Üç eksenli basınç deneyinde standart Proctor sıkılığında sıkıştırılmış zemin numunelerinin CBR değer ortalamas $1 \% 12$ civarında olan numunelerin drenajs1z kayma dayanımı, 76,78-68 kPa arasında ortalama $72 \mathrm{kPa}, \mathrm{CBR}$ değer ortalaması $\% 8,8$ civarında olan numunelerin drenajsız kayma dayanımı $62,43-56,04 \mathrm{kPa}$ arasinda ortalama $60 \mathrm{kPa}$ ve CBR değer ortalaması $\% 6,2$ olan numuneler $58,62-52,39 \mathrm{kPa}$ arasında ortalama $55 \mathrm{kPa}$ drenajsız kayma dayanımı değeri vermiştir. Deney sonuçları Çizelge 6'da verilmiştir.

Çizelge 6. Deney Sonuçları

\begin{tabular}{|c|c|c|c|c|c|c|}
\hline Deney Ad1 & Su İçeriği & $\operatorname{Sr}(\%)$ & $\begin{array}{c}\text { CBR\% } \\
\text { (Ort.) }\end{array}$ & $\begin{array}{c}\mathrm{Cu} \\
(\text { Ort..kPa })\end{array}$ & $\begin{array}{c}\text { İçsel Sürtünme } \\
\text { Açı1 (Ort.) } \\
\phi\end{array}$ & Bulunan Katsay1 \\
\hline SP1 & $\% 30,5$ & 90 & 12 & 72,86 & 26,86 & 0,167 \\
\hline SP2 & $\% 34$ & 94 & 9 & 59,68 & 17,31 & 0,162 \\
\hline SP3 & $\% 36$ & 97 & 6 & 56,08 & 11,95 & 0,111 \\
\hline
\end{tabular}

Deneylerden elde edilen sonuçlar Çizelge 7' de Look'un Handbook of Geotechnical İnvestigation and Desing Tables kitabında verdiği, daha önce yapılan deneylerden elde edilen verilere göre değerlendirildiğinde, Look'da drenajsı kayma 
dayanımlarinin CBR sonuçları artışı ile arttığı görülmektedir. Look killeri sertlik değerine göre ayırmış bu değerlerden elde edilen CBR sonuçlarından da elde edilecek ortalama drenajsız kayma dayanımı hakkında yaklaşık tahminlerde bulunmuştur. $\mathrm{Bu}$ değerlendirmeye göre CBR değerinin 4-10 arasında olması durumunda drenajsız kayma dayanımının 50-100 kPa, 10-20 arasinda olması durumunda $100-200 \mathrm{kPa}$ ve CBR $>20$ olmas1 durumunda da drenajsız kayma dayanımı > $200 \mathrm{kPa}$ gibi değerlerde olabileceğini öngörülmüştür. Yaptığımız çalışmalardan elde ettiğimiz CBR değerleri ile Look (15) karşılaştırıldığında, standart Proctor sıkılığında ortalama CBR değeri \%6-\%12 arasında değişen zeminler katı sınıfına girmekte ve drenajsız kayma dayanımları $55-72 \mathrm{kPa}$ arasında değiştiğ görülmekte olup elde edilen sonuçların çok farklı olmadığı görülmüştür.

\section{Çizelge 7. Look'a göre CBR değerleri ile drenajsız kayma dayanımı arasındaki yaklaşık korelasyon ve laboratuvar sonuçları arasındaki ilişki[15]}

\begin{tabular}{|c|c|c|c|c|c|c|c|}
\hline \multicolumn{2}{|c|}{ Zeminin Kıvamı } & Yumuşak & Sık1 & Kat1 & Çok katı & Sert & Çok sert \\
\hline $\begin{array}{c}\text { Yaklaşık } \\
\text { CBR (\%) }\end{array}$ & Örselenmemiş & - & $1-2$ & $2-4$ & $4-10$ & $>10$ & \\
\hline \multicolumn{2}{|c|}{$\begin{array}{c}\text { Örselenmiş } \\
\text { Look'a göre Drenajsız Kayma } \\
\text { Dayanımı (kPa) }\end{array}$} & $1-2$ & $2-4$ & $4-10$ & $10-20$ & $>20$ & \\
\hline \multicolumn{2}{|c|}{ CBR Değerleri (ort) } & $12-25$ & $25-50$ & $50-100$ & $100-200$ & $>200$ & \\
\hline Drenajsız Kayma Dayanımı (kPa) & 55 & 8,8 & 12 & 38 & 59 & 68 \\
\hline
\end{tabular}

\section{Sonuçlar}

Yapılan CBR ve üç eksenli basınç deneyleri ile bulunan drenajsız kayma dayanımı değerleri ortalamasına bakıldığı zaman, deney yapılan kil numunesi ile arasında genel olarak standart proctor sıkılığındaki zeminlerde; Aşağıdaki eşitlikte gösterildiği gibi (Eş.1) karektersitik bir davranış göstererek bu aralılarda değiştiği görülmüştür.

$C B R=C u x 0,111 \sim 0,167 \quad$ Eş. (1)

Bulunan bu katsayılar, her zeminin kendine özgü bir değerinin olduğunu ve su içeriği değişikliği ile bu değerin değişim gösterdiğini ortaya koymaktadır. Katsayı seçiminde doygunluk yüzdesinin artışına bağlı olarak katsayılarında büyüdüğü göz önüne alınmalıdır. Optimum su içeriğinde katsayı 0,111 civarında olurken, optimum su içeriğinin üzerindeki su içeriklerinde katsayının 0,167'ye kadar değişim göstermektedir.

\section{Kaynaklar}

[1].Tunç, A. 2004. Kaplama Mühendisliği ve Uygulamaları. Asil Yayın Dağıtım, Ankara

[2]. Uzuner, Bayram Ali (2005). Temel Zemin Mekaniği. Trabzon.

[3].Türedi, Y., Örnek, M., Bal, B.H., Işık, A. O. (2017). Çelikhane Cürufu Katkısının CBR Sonuçlarına Etkisinin Araştırılması. 7. Geoteknik Sempozyumu 22-23-24 Kasım 2017, İstanbul.

[4].Vural, İ. (2016). İnşaat Yıkıntı Atıkları ile Zeminlerin Taşıma Gücü Özelliklerinin İyileştirilmesi. 4th International Symposium on Innovative Technologies in Engineering and Scicene 3-5 November 2016 (ISITES2016 Alanya/Antalya Turkey).

[5].Erginer, M., Kahraman, O., Ersin, A.B., Türedi, Y., Örnek, M. (2019). Lastik Atık Katkılı Zeminlerde CBR Değerinin Araştırılması. OKÜ Fen Bil. Enst. Dergisi, Cilt 2, Sayı 1, 41.44.

[6].Kök, B.V., Yılmaz, M., Geçkil, A. (2012). Çimento Stablizasyonlu zeminin Esnek Üst Yapı Maliyetine Etkisi. Pamukkale Üniversitesi Mühendislik Bilimleri Dergisi, Cilt 18, Sayı 3, S.165-172.

e-ISSN: 2148-2683
$\mathrm{Bu}$ çalışmada, başlangıçta planlama yapılırken numuneler normal şartların dışında, suda bekletilerek tam doygun durumdaki su içeriklerinde CBR değerleri ile üç eksenli kayma dayanımları ölçülmek istenmiştir. Numuneler 10 gün suda beklemesine rağmen içeriğindeki yüksek plastisiteli kilden dolayı tam doygun duruma getirilemediği için su içerikleri arttırılarak \%100 doygun duruma getirilmeye çalışılmıştır. Bu tür zeminleri suda bekleterek doygun duruma getirmek isteyen başka çalışmacılara numuneleri farklı şekillerde (geri basınç altında bekletme gibi) doygun duruma getirerek deney yapmaları önerilir.

Ayrıca CBR deneyleri ile diğer kayma dayanımı deney sonuçları ve deformasyon parametreleri (elastisite modulü, hacimsel sıkışma indisi gibi) ile de değerlendirilmesinin konuya daha fazla katkı sağlayacağı düşünülmektedir.

[7]. Yaşar, M. (2019). Uçucu Kül Katkısının Kilin Geoteknik Özelliklerine Etkisi. Yüksek Lisans Tezi. Bartın Üniversitesi, Bartın.

[8].Geçkil, T., Sarıcı, T., Karbaş, B.(2021). Siyah Karbon ile Stabilize Edilen Taban Zeminin Yol Esnek Üst Yapı Maliyetine Etkisi. Avrupa Bilim ve Teknoloji Dergisi Sayı 23, S. 222-235.

[9]. ASTM D 1883.(2016). Standard Test Method for California Bearing Ratio (CBR) of Laboratory-Compacted Soils. Washington, D.C.

[10].Çelik M.H., Orhan, M., Ongun, Y. (2005). Balgat ve Etimesgut Bölgesi Kilinin Zemin İndekslerinin ve Parametrelerinin Değerlendirilmesi. Politeknik Dergisi, Cilt:8, Sayı:1, S.87-94.

[11]. Öztürk, Y., S., Ünsal, N., Akbaş, S.O. (2015). Gölbaşı (Ankara) Yerleşim Alanını Killerinin Şişme Ve Kireç İle İyileştirilme Potansiyellerinin Belirlenmesi. Gazi Üniv. Müh. Mim. Fak. Der, Cilt 30, No 2, 309-318.

[12]. Akyürek, B., (1997). 1/1000000 ölçekli ve açınsama nitelikli Türkiye Jeoloji Haritaları Serisi, Ankara: MTA Yayını Ankara-F15 paftasi. 
[13]. Yılmaz, U., (2006). Ankara Kilinin (Çankaya-Ankara) Slkışma-Kabarma Özelliklerinin İncelenmesi, Yüksek Lisans Tezi, Süleyman Demirel Üniversitesi F.B.E, Isparta, 27.

[14].ASTM D 698 (2012). Standard Test Method for Laboratory Compaction Charecteristics of Soil Using Standar Effort. Washington, D.C.
[15]. ASTM D2850 (2015). Standard Test Method for Unconsolidated-Undrained Triaxial Compression Test on Cohesive Soils. Washington, D.C.

[16].Look, B. (2007). Handbook of Geotechnical İnvestigation and Desing Tables. Netherlands: Taylor\&Francis, 157. 